\title{
Producing Intellectual Labor In The Classroom: The Utilization Of A Critical Thinking Model To Help Students Take Command Of Their Thinking
}

Phillip Crenshaw, East Central Community College, USA

Enoch Hale, Foundation for Critical Thinking, USA

Sallie L. Harper, Mississippi State University-Meridian, USA

\begin{abstract}
A review of the literature reveals that although the teaching of critical thinking skills is a significant aim of post-secondary pedagogy, much ambiguity exists regarding the topic. In fact, due to the lack of faculty familiarity with the concept compounded by student resistance to put forth the intellectual labor to take charge of their own thinking, matriculates are mainly exposed to didactic instruction that does not prepare them with real-world problem solving skills. This manuscript addresses these problems in the following way. First, it outlines a foundational conception of critical thinking as articulated by the Foundation for Critical Thinking. In doing so, it comments on the importance of student-centered instruction as key to fostering critical thinking skills and dispositions in the classroom. Second, it canvasses an example of what critical thinking instruction and learning can look like.
\end{abstract}

Keywords: critical thinking; pseudo-critical thinking; didactic Instruction; Infusion; elements of thought; intellectual standards; Intellectual virtues; egocentrism

\section{INTRODUCTION}

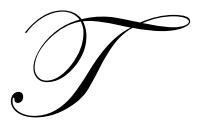

he concept of critical thinking has not always experienced the visibility and emphasis as it does in today's educational, business and political environments. The review of the literature reveals that higher education, in particular, is now placing an overwhelming emphasis upon exposing matriculates to the concept of critical thinking and challenging them to develop those skills and dispositions necessary for improving the quality of their lives as individuals and members of a global community (Bradford, 1987; Tsui, 2008; The Foundation for Critical Thinking, n.d.). Moreover, this emphasis was punctuated by the Federal government. Specifically, critical thinking was stated by the National Educational Goals Panel as a significant aspect of education and more recently, by President Barak Obama, who stated that one of the keys to a workforce equipped to handle $21^{\text {st }}$ Century problems is the development of critical thinking skills and abilities (Halper, 1999; Jackson, 2009). That being said, numerous barriers to the substantive cultivation of critical thinking in the classroom continue to exist.

Some argue that the absence of a single definition or conception of critical thinking acts as a barrier to developing focused action plans for cultivating associated skills and dispositions. Others cite student resistance to the required intellectual labor as a primary obstacle, and still others argue that faculty sciolism regarding the contextualization of the concept constitutes a significant obstruction to the successful implementation of critical thinking into curriculum, instruction, and school culture (Bailin, Case, Coombs, \& Daniels, 1999; Browne \& Freeman, 2000; Barak \& Shakhman, 2008; Wright, 2002). Furthermore, the review of the literature on the topic of critical thinking, teaching and learning reveals multiple methods by which critical thinking is contextualized; accentuating the difficulty some instructors may experience when attempting to account for the general, and 
sometimes institutional, mandate to foster critical thinking in their learning environments (Plath, English, Connors, \& Beveridge, 1999).

The purpose of this paper is two-fold. First, it will be argued that despite the seemingly unclear nature of critical thinking, a core conception of critical thinking, with shared foundations and purposes, can be documented when we look closely at the works of scholars who have articulated the concept. This conception represents a foundational intellectual language, that when used with discipline can contribute to the development of critical thinking skills and dispositions. Secondly, this paper will evince the educational practices utilized during the infusion of one cross-disciplinary model with Western Civilization courses instructed by Dr. Phillip Crenshaw. The model chosen focuses on foundational critical thinking concepts and principles as articulated by fellows at the Foundation for Critical Thinking.

\section{The Significance Of Critical Thinking}

Thinking critically can enhance individual quality of life. First, critical thinking creates better decision makers. In other words, it is a survival [emphasis added] skill utilized in numerous areas of life. For example, it is essential to solving problems faced by individuals in disparate contexts, such as parenting, the workforce, politics, and citizenship (Johanson, 2010; Lehman \& Nisbett, 1990; Nosich, 2009). This point of view was accentuated by Bradford (1987):

When people actively apply critical thinking concepts and use constructive behaviors, they develop more ideas, make fewer mistakes and reach better decisions. But when people act on beliefs they have not carefully thought through, they will shoot down ideas even before they are understood, or take action based upon faulty assumptions (p. 9).

Secondly, the state of the nation's workforce is dependent upon the possession of critical thinking skills due to the context of ever-accelerating change (Paul, 1995). Specifically, employers have admitted they are dependent upon post-secondary education curriculums to evince critical thinking skills to enhance the viability of employer problem solving and decisions making (Halpern, 1998). Robinson (2000) stated that employers have realized the lack of employee critical thinking skills has created a skills-gap. Thus, the consensus has been reached amongst the economic community that higher order thinking skills play a significant role in long-term employment due to these individuals possessing the skills that make that increase their ability to succeed in advanced workplace training. That said scholars have failed to reach a consensus regarding how to succinctly define the concept.

\section{Conceptualization Of Critical Thinking}

There are nearly as many definitions of critical thinking as there are publications on the topic. Every definition of critical thinking reflects to some degree a certain disciplinary point of view more appropriate to particular contexts; each definition contributes interpretations and insights that others do not necessarily explicate; when examined closely, however, common principles are present; these common principles form a base-line conception of critical thinking that works within and moves across disciplinary boundaries. In this sense, a crossdisciplinary interpretation of critical thinking is most consistent with the history of the concept and the ideals of a liberal education. However, some scholars argue that the failure to foster critical thinking within education is related, in part, to the lack of consensus in establishing a common definition (Fasko, 2003b; Fung, 2005; Moseley et al., 2005; Walters, 1999). Yet a brief examination of the discourse on critical thinking reveals that significant disagreement lies less with its definitions and more with the way the concept is conceptualized within specific domains and educational settings. An examination of the idea itself reveals a substantive and robust conception that crosses disciplinary boundaries and reinforces the general skills and dispositions that complement their specialized manifestations. Such a conception of critical thinking explicates understandings essential to thinking well within every domain of human thought and life and is based on the goal of fostering a disciplined use of a thinking language (Paul, 1995). Specifically, employers have admitted they are dependent

At its core, critical thinking concepts represent sets of vocabulary or terms that lead to the development of associated skills when the necessary intellectual labor is contextually engaged. The use of thinking terms requires 
deep understanding and repeated application across a variety of contexts in order for them to prove themselves useful in developing critical thought. A cohort of scholars from the fields of psychology and education argue in their book, Frameworks for Thinking: A Handbook for Teaching and Learning, "Without a vocabulary to describe aspects of thinking that we believe to be teachable it is hard to develop teaching approaches or pedagogies that are effective" (Moseley et. al., 2005, p. 8). This position is similarly articulated by Tishman, Perkins and Jay (1995) at Harvard University's Project Zero. In their book entitled The Thinking Classroom: Learning and Teaching in a Culture of Thinking, it is argued that "The language of thinking helps students organize and communicate their own thinking more precisely and intelligently." Furthermore, a rich and robust language that provides students with words to describe their thinking "communicates and reinforces standards of thinking" well (pp. 12-13). The language of thinking well is the language of critical thinking, and an examination of the literature reveals common concepts within the many proposed definitions of critical thinking.

Every academic discipline has significantly contributed to understanding and solving human problems. Each has developed some technical language and methods to think critically within its domain. However, specialized language and methods are often not understandable, applicable, and accessible to people outside the technical discourse. Furthermore, problems of specialization in academia are similar to problems of compartmentalization in the individual's mind. Critical insights from one domain do not necessarily transfer to other domains in a way that helps one improve his/her thinking in general (Hale 2008). A substantive, cross-disciplinary model of critical thinking offers a way of approaching thinking so that it works critically within, across and beyond all domains and is intuitive to educated persons. The Foundation for Critical Thinking articulates and advocates one such model.

\section{The Foundation for Critical Thinking Model}

The Foundation for Critical Thinking's model, promulgated by Dr. Richard Paul and Dr. Linda Elder, is based upon the amalgamation of concepts - although not exhaustive - deemed cross disciplinary cannons of scholarship [emphasis added] wherever high quality thinking is found. Specifically, these concepts are associated with elements of reasoning, intellectual standards and dispositions Paul and Elder refer to as intellectual virtues. All three are considered necessary conditions for strong -sense critical thought (Hale, 2008). According to Paul \& Elder (2006), the characteristics of strong-sense thinking are as follows: (a) a consistent pursuit of the fair and just, (b) an ethical disposition, (c) empathizing with the viewpoints of others, (d) entertaining opposing points of view, and (e) changing views when faced with better reasoning (pp. 2-4). The strong-sense critical thinker skillfully enters into the logic of problems and issues to see the problem for what it is without egocentric and/or socio-centric bias. Thus conceived, the strong-sense mind seeks to actively, systematically and reflectively construct the insight with sensitivity to expose and address the many obstacles that comprise high quality thought. Reciprocally, the weaksense critical thinker is a highly skilled but selfishly motivated pseudo-intellectual who works to advance one's personal agenda without seriously considering the ethical consequences and implications. In this sense, the weaksense critical thinker is often highly skilled but uses those skills selectively so as to pursue unjust and selfish ends (Paul, 1995). The thinker who consciously, systematically, consistently, and fair-mindedly analyzes and evaluates his/her thinking so as to avoid distortion (unintentional and intentional) moves toward developing those skills that characterize what it means to think critically in a strong-sense way. A language comprised of foundational critical thinking concepts can act, when substantively engaged, as a network of question generating ideas the purpose of which is to better understand the thinking that guides decisions, actions and beliefs and can check those cognitive tendencies that distort reality. The elements of reasoning, intellectual standards and intellectual traits provide such a language (Hale, 2008; Nosich, 2009; Paul \& Elder, 2006).

\section{The Elements of Reasoning}

According to Paul (1995), "the elements of thought are the basic building blocks of thinking, essential dimensions whenever and wherever it occurs (p. 124) (see Appendix A for the Elements of Thought). The following statements illustrate this point: 
Whenever you are reasoning, you are trying to accomplish some purpose, within a point of view, using concepts or ideas. You are focused on some question, issue, or problem, using information to come to conclusions, based on assumptions, all of which have implications (Paul \& Elder, 2006, p. 57).

According to Paul and Elder (1996), flaws in one's thinking cannot be ascertained without some type of substantive engagement with the various elements of thought. Although this engagement is often implicit, Paul and Elder argue that consciously using the concepts to generate reflective and analytical questions will provide one with a framework to systematically enter into the analysis of their thinking and the thinking of others. Making the ideas explicit increases the probability that certain questions will be asked as opposed to solely relying on one's intuitive experience to ask all the relevant, probing questions (Hale, 2008). Thus, critical thinkers routinely enter into the logic of thinking by posing probing questions such as:

- What is the purpose of my thinking?

- What is the question at issue? Is the question clear and precisely stated?

- Within what point of view am I thinking?

- What information am I using and where did I obtain this information?

- What concepts or ideas are central to my interpretation?

- What assumptions am I making? Are they valid?

- What conclusions have I drawn? Are they logically sound?

- If I accept the conclusions, what are the implications? (Paul \& Elder, 1995, p. 22).

According to Elder \& Paul (2010), when one seeks to systematically uncover and enter into the logic of one's thinking and/or the thinking in question then the thinker is in a better position to check those more pervasive tendencies that cause thinking to error. In other words, gaining knowledge of the fundamental parts of thinking and disciplined practice in applying them within contexts helps one avoid bias, prejudice, exaggeration, overgeneralization, and self-deception.

\section{Standards For Evaluating Thinking}

One can analyze thinking, but do so poorly. Substantive analysis and synthesis involves the disciplined application of appropriate criteria that ensures its high quality. Matthew Lipman's (1995) definition of critical thinking explicates the necessary role evaluative criteria play in thinking critically. He writes, "Critical thinking is skillful, responsible thinking that is conducive to good judgment because it is sensitive to context, relies on criteria, and is self-correcting" (p. 116 ). Paul echoes Lipman's inclusion of assessment criteria in thinking critically. According to Paul (1995), "there can be no critical thinking without the use of intellectual standards" (p. 55). (see Appendix B for The Intellectual Standards). The intellectual standards are those canons of scholarship that characterize high quality thinking and are present wherever high quality thinking exists. The disciplined use of intellectual standards helps prevent the tendency to assess the value or worth of something using egocentric or sociocentric standards such as fun, exciting, beneficial to me, advantageous, and so forth (Elder \& Paul, 2008; Nosich, 2009). Intellectual standards are innumerable and the context determines which standards are relevant to a particular line of reasoning. Paul and Elder list nine standards that have high use in pedagogical contexts. Nosich (2009) advocates additional standards including: reasonable, logical, rational, consistent, testable, well-organized and valid. Apropos to this, Hale (2008) argues that, as far as the classroom is concerned, articulating and applying intellectual standards provides students with a clear framework that can be used to develop an intellectual language that applies to thinking across the disciplines. It thus establishes a common language in the classroom that can help create a culture of learning and disciplined thinking.

\section{The Intellectual Traits}

Egocentrism is the most significant barrier to the development of critical thinking (Foundation for Critical Thinking, 1995). Once again, the disciplined use of a language based on foundation critical thinking concepts can help one take command of his or thinking. The third part of the Paul-Elder model is labeled the intellectual traits (See Appendix C for The Intellectual Traits of Mind). These traits are dispositions or, as Costa (2001) articulates 
them habits of mind, that characterize the strong-sense critical thinker. The traits of mind represent the ideal attitudes and behaviors of those who think critically. They are those characteristics that are the fundamental aim of critical thinking and education. Linda Elder (2011) states the "main focus should be the cultivation of intellectual virtues. When one ignores these traits while teaching intellectual skills, we unwittingly foster sophistic thinking, or the opposites of the intellectual virtues - intellectual arrogance, intellectual hypocrisy, intellectual cowardice, intellectual conformity, narrow-mindedness and the like" (p.2). Thus, if these traits are not valued, strong-sense critical thinking cannot occur due to the lack of fair-mindedness (Paul \& Elder, 2006).

\section{Post-Secondary Education And Its Relationship To Critical Thinking}

The ultimate purpose of higher education is to aid matriculates in learning to think critically (Browne \& Freeman, 2000; Gmelin, 2010; Johanson, 2010; Mejia \& Malinn, 2007; Van Gelder, 2005). Ennis (1985) stated: "There is much more cognitive stuff to be acquired in school [all levels] than elementary reading, writing, arithmetic and banks of memorized and soon-to-be-forgotten facts" (p. 45). Indeed, today's educational climate is not conducive to promoting critical thinking, especially in the realm of staff development (Paul, Elder, \& Bartell, 1997). That being said, two significant problems serve as barriers to this goal. According to the literature, the first barrier lies with the instructor. Although it is noted that faculty actions in the classroom impact student development in critical thinking, the majority of instructors - at all levels of academia - are not prepared to facilitate the learning of critical thinking skills. The reason being is that many educators believe they have inherited [emphasis added] the skills of critical thinking by virtue of their respective education; thus generating the belief they serve as sufficient critical thinking models for their students (Halpern, 1999; Pascarell \& Terenzini, 2005; Paul, Elder, \& Bartell, 1997; Tsui, 2008).

Regarding higher-education faculty, researchers revealed the majority of faculty support critical thinking as a significant aspect of their pedagogy, and how to contextualize associated skills within their respective pedagogies; thus didactic instruction takes precedence (Balin Case, Coombs, \& Daniels, 1999; Elder, 2010; Van Gelder, 2005; Wright, 2002). Also, a study conducted by Barak and Shakhman (2008) evinced data that the population of instructors possessed only little knowledge about that which accounts for or characterizes higher-order thinking skills. In contrast, Browne \& Freeman (2000) advocated the point of view that "deference to critical thinking as an educational objective is more common than the active encouragement of critical thinking in university classrooms (p. 301). Secondly, the problem with the facilitation of critical thinking in the post-secondary classroom lies with the student population. Succinctly put, the majority of post-secondary students are not prepared to think critically (Angelo, 1995; Gross, 2009). Also, college students resist learning higher order thinking skills due to the intellectual labor required in contrast to merely absorbing information (Bughussian, 2006; Halx, Mark, \& Reybuld, 2005). Consequently, college instructors must develop educational theories and practices that facilitate the development of critical thinking skills and dispositions (Gross, 2009).

\section{Critical Thinking And Pedagogy}

Various points of view exist regarding the most effective methods and approaches for helping students develop valuable critical thinking skills. Interrogatively stated, "How might we teach for the development of critical thinking" (Mason, p. 344). Ennis (1989) identifies four approaches: General, infusion, immersion, and mixed. Plath, English, Connors and Alex (1999) provide a succinct description of each category.

- The General Approach: Critical thinking is taught is a course designed only for the learning of associated skills.

- The Infusion Approach: Critical thinking skills are taught within a specific subject and students are encouraged to "think through" the content as opposed to memorizing facts.

- The Immersion Approach: This approach is similar to the infusion approach, except students are not made aware of the concepts and thinking strategies they are implicitly learning.

- The Mixed Approach: Using this approach, students are introduced to critical thinking concepts and thinking strategies in a general course then apply those concepts in their respective disciplines. 
These approaches constitute a framework of sorts that can aid one in the clarification and organization of his/her instructional design. Nonetheless, just as teaching is not an exact science, so too is teaching students to think critically. Likewise, just as there are multiple ways to conceptualize critical thinking, there are multiple methods and approaches by which to foster its development. What is consistent, however, is the recognition that in order for higher order thinking skills to develop students must be actively engaged [emphasis added].

Active engagement involves more than having students participate in a particular instructional strategy. The art of teaching and learning is found in the dynamic interaction of ideas and methods for thinking about ideas with sensitivity to the context of the classroom culture and content. Some of the various methods that can lead to active critical engagement include modeling, conceptual analysis, problem based learning, cognitive dissonance, Socratic questioning, critical reading and writing, and role-playing. In every case, however, students are challenged to critically reason through a problem or issue. In doing so, there is ample evidence to show the necessary role questioning plays as a tool for thinking critically (Angelo, 1993; Browne \& Freeman, 2000; Bughussian, 2006; Elder, 2010; Gross, 2009; Halx, Mark \& Reybuld, 2005; Nosich, 2009; Pattiz, 2004). Questioning is implicit within all of the aforementioned approaches for actively engaging student thinking. The topic of questioning itself is a topic of significant study, but for the purposes of this paper it is argued that equipping students with a question generating language can provide students with an opportunity to develop critical thinking skills and dispositions. As instructors and students gain familiarity with a foundational critical thinking language, they will be in a better position to ask probing and insightful questions. The pedagogical method for substantive student engagement outlined in the next section is based on the idea of helping students gain a deep understanding of question generating concepts that aid them in the construction of content knowledge and self-discovery.

\section{Implementation Of The Foundation For Critical Thinking Western Civilization Classes}

Three purposes inform the pedagogical approach to fostering critical thinking canvassed in this paper. The first objective is to help students gain knowledge of basic historical facts and events deemed important both by the instructor and curriculum guidelines. The second goal is to facilitate the substantive engagement of foundational critical thinking concepts that when contextualized lead to the development of critical thinking skills. The third purpose is to aid students in the development of self-reflective and metacognitive skills by applying the course content and explicit critical thinking strategies across disciplines and to their personal lives. To accomplish these goals, the concept of active learning, as opposed to didactic, is central to the instruction and learning where the primary method of engagement is that of infusion. With this in mind, the general instructional approach is organized by the following components: (a) frontloading, (b) engaged lecture based on the Socratic Method, (c) Debriefing/Recapitulation, and (d) Evaluation/Assessment. The case highlighted for this paper concentrates on a lesson that investigates the Black Death that swept over Western Europe in the $14^{\text {th }}$ Century. This topic is addressed in a series of three sessions each of which is held for a duration of 50 minutes.

\section{Frontloading}

Critical thinking begins with questions. When students enter the classroom, they are asked to record the lesson's key questions listed on the board. As learners become more adept at questioning they are challenged to develop questions that identify problems and issues to be addressed. Organizing questions presented to students regarding the Black Death included:

- What was the context of the Black Plague?

- $\quad$ Can you clarify what the Black Plague was?

- $\quad$ Can you elaborate precisely elaborate upon how it was spread?

- What was the context of the Black Plague?

- What were the consequences of the Plague upon the social order?

After students record the lesson's focus questions, learners are asked to read a passage from an assigned text. In doing so, they are directed to read for the following purpose: find precise information that established the context for the Death's entrance into Western Europe. Subsequently, students are challenged to voice what they found with a partner and/or in whole-group discussion, while classmates evaluated the information for accuracy. 
Students are then directed to a new but related question: Do you see evidence of these characteristics in contemporary society? Students attempt to address the question in a discussion and/or a short writing. Working on the question is an attempt to help students draw connections to their personal lives so that they become invested in the content which is important for this particular population. Finally, in order to create a sense of transference, the students will view a short clip from the film, Outbreak. During the film, students are asked to look for precise symptoms and to reach a conclusion regarding how the virus was spread, which serves as an anticipatory activity, or primer, for studying the Black Death.

\section{Engaged Lecture Emphasizing Socratic Discussion}

The engaged lecture begins with the question: How was the Black Death spread? Learners are asked if they have any prior knowledge of the causes leading to the mass deaths that swept Europe due to the disease. Having students acknowledge their existing knowledge, and its limits, aids in the cultivation of the critical thinking disposition of intellectual humility because students minds are positioned to fill in any information gaps that are relevant and necessary to settle the lesson's organizing questions. Next, in order to reinforce the skill of clarification, students view a diagram that illustrates how rapidly the Black Death spread over Europe. To promote Intellectual Humility students are encouraged to express the limits of their knowledge regarding how the Death spread, using the following website as an information source with which they can compare their previous knowledge and understanding: http://www.insecta-inspecta.com/fleas/bdeath/Black.html. As the students viewed the diagram, they are asked to reach a precise conclusion regarding the key variables involved in the spreading of the plaguewhole-group discussion emphasizing accuracy ensures an accurate conclusion. After reaching an accurate conclusion, the students are challenged with the following question: What conditions in Western Europe created the context for the growth in the black rat and flea populations? In order to answer the question, the students are given an article to read for the purpose of highlighting precise information relevant to the preceding question. After students answer questions relevant to this task, the following question was asked: What were the mortality rates? [It is at this time the instructor changed into a Grim Reaper costume and played the song, Death, by Judas Priest as the students read a passage from the text that gave precise examples plus an overall estimate]. The utilization of the arts generates better focus amongst the students while at the same time providing an opportunity for the instructor to ask the following question: Do you believe the costume and music relevant to the lesson?

The next thematic aspect of the lesson dealt with the breakdown in Western Europe's social order. To focus student attention on this theme, the following question is posed: What precise consequences did Hurricane Katrina have upon the social order of New Orleans? Relevant songs and demonstration are utilized to clarify the points made in the text. For example, the process occurred as follows. First, students read a historical reaction to the plague from a primary source. For example, the first reaction was "live for the moment". Thus, the instructor role-played this type of individual by wearing an 80's-type Hair Metal Band wig, pretending to drink from a beer bottle, while "Nothing But a Good Time" by Poison played in the background; the purpose of this use of the arts is to illustrate the philosophy of disregarding consequences resulting from a fatalistic point of view. Second, this source discusses groups of wanderers, called flagellants that believed they could prevent the plague from entering a town by flogging themselves. After the students read an eyewitness account, the instructor clarified this by using my belt to whip himself-lightly striking his body — while Michael Jackson's "Beat It" played in the background. After each song, the instructor asks the students if they see the relevance of the song to the passages they read. By the way, after each song, the instructor would always ask the students if the believed the songs were "relevant" to the passage. Finally, the matriculates entertain the notion of the "blame game" by first turning to the glossary in order to state the meaning of the key concept, "pogrom". Next, in order to clarify, students read a primary document from the text that precisely described the burning of 2000 Jews. Next, the students read the text to find the precise reason. Once the reason is found, the students are asked them to place themselves in that time period and to use the relevant elements and standards to "think though" the claim.

\section{Debriefing}

Utilizing whole-group discussion, the Black Death lesson was debriefed via the following question: Do you believe nature automatically creates a condition such as the Black Death when a population grows to the point 
where it cannot sustain itself? In an attempt t provide the context for knowledge transfer; students are encouraged to cite evidence from the lesson as they reason through the problem.

\section{Evaluation}

Formal evaluation occurs within the unit test, which will evince some of the following types of questions related to this thematic unit:

- Would an anti-Semite advocate a pogrom? (clarify by stating your answer in one broad sentence, elaborate in other words, and then exemplify)

- $\quad$ You are a flagellant. That said, what would be your point of view towards natural disasters? Use the following formula: When I look at natural disasters, I see . To explain... [be sure to utilize transitions

- Do you believe the world is facing an imminent pandemic? (clarify by stating, elaborating, and exemplifying)

However, informal assessment of student learning is present throughout the engaged lecture process. The instructor regularly probes student understanding by posing questions for clarity, depth, relevance, significance, order, causation, implications, etc. For example, when asked to explore the relevance of a particular song to the content of the Black Plague, students are expected to make conceptual and evidenced-based connections. Furthermore, students are challenged to clarify the concepts and claims they use in their discussions and written compositions. The assessment of critical thinking skills and dispositions is a dynamic process that cannot be limited to a single form of evaluation. Rather, evaluation must be robust in that it addresses the manifestation of a specific skill in a variety of contexts and modalities.

The assessment goals in this course are based upon generating active learning by requiring students to "think through" the course content. It is the instructor's hoped that students will gain adequate knowledge of the concepts and skills so that the disposition to think critically becomes part of their daily behavior and worldview. Thus, the goal is that students will not only exhibit greater intellectual labor in class, but also transfer the historical information to their daily lives and utilize critical thinking across the curriculum and in their daily decision making. As a consequence, student questioning becomes more commonplace as the semester progresses. For example, students ask questions such as: (a) Can you give an example? (b) Can you elaborate? (c) What is your source? (d) How was this information justified? In addition, during the previously mentioned lesson, students asked some of the following questions: (a) How did one become a member of the flagellants? (b) How can someone claim to be a Christian and advocate the burning of Jews? (c) What was the logic behind those that believed the Jews were poisoning European wells? (d) Why does religion seem to promote violence? On a personal note, the instructor has noticed more students utilizing the critical thinking language to voice problems within their daily lives. For example, one student used the concept of implications to share how her husband was creating problems within her marriage. Also, after being introduced to the concept of credibility, many students - unprompted — when given extra credit assignments would bring a hard copy of their source to show credibility. Furthermore, the impact of this pedagogy outside the classroom environment was evidenced when a student informed the instructor that critical thinking was the reason he was getting into a Master's level nursing program. When asked for clarification, he stated that the nursing instructors at our institution informed him he did not qualify for a Master's program, but instead of ending his pursuit, he considered alternatives, which later led to his discovery of an institution that he qualified for. Thus, the student's knowledge of the "alternatives" concept was the reason he refused to quit! To top things off, at the end of the semester, the instructor's evaluation data overwhelmingly showed students - those that stick it out because this type of course requires much intellectual labor-are proud of their new thinking abilities and are transferring them to everyday situations.

\section{CONCLUSION}

The topic of critical thinking continues to hold a prominent place in education. Despite views that there is not a cohesive definition of critical thinking the literature reveals sets of concepts and principles that crossdisciplinary boundaries. These ideas constitute a base-line conception that can be utilized as an intellectual language 
in the classroom; a language that, when substantively and explicitly engaged, can provide students with question generating ideas that probe both the logic of the subject matter and student lives. This paper applied one such conceptual framework as articulated by Fellows at the Foundation for Critical Thinking in a series of Western History community college courses. The results of explicit instruction and engagement with foundational critical thinking concepts were that students were better prepared to do the intellectual work necessary for content mastery and self-reflection. Although the extent to which measurable critical thinking skills are cultivated through such engagement over the course of one semester is questionable, initial results (as exemplified by course performance and student feedback) reveal that instruction that focuses on active learning through engaged lectures and the disciplined use of a question generating language helps students develop greater awareness of course content and self. Furthermore, such approaches are ripe for longitudinal studies so that the question of critical thinking skills can be addressed. What seems to be true, however, is that the development of critical thinking skills is related to the intellectual labor students and instructors put into their work.

\section{AUTHOR INFORMATION}

Dr. Phillip Crenshaw is a teacher of Western Civilization and American History at East Central Community College in Decatur, MS. Before arriving at East Central Community College, he garnered 13 years experience in the High School context. He is also a member of the Foundation for Critical Thinking and has presented at the three previous International Conferences hosted by the Foundation. Dr. Crenshaw's passion is the infusion of the Foundation's Critical Thinking Model into his discipline.

Dr. Enoch Hale is a Fellow at the Foundation for Critical Thinking. He teaches a graduate course for instructors on practical methods for infusing critical thinking into instruction and curriculum. He began his career as a high school social studies instructor where he took a systematic approach to infusing critical thinking into the classroom. Dr. Hale has facilitated over 100 professional development workshops for instructors at all educational levels both nationally and internationally. His research interests include critical thinking across the curriculum, teacher education, and practical instructional strategies that foster higher order thinking for all students.

Dr. Sallie Harper is the Interim Associate Dean and an Associate Professor in Curriculum, Instruction, and Special Education at Mississippi State University-Meridian. Dr. Harper is also a consultant for East Mississippi Center for Educational Development, and has over 85 presentations at the state level on art integration, early childhood mathematics, and science. She has over 28 years of experience in the field of elementary education at the public school and university levels. Sallie has published 15 articles in the areas of teacher education and elementary mathematics instruction, and has 25 international and national presentations.

\section{REFERENCES}

1. Angelo, T. (1995). Beginning the dialogue: Thoughts on promoting critical thinking. Teaching of Psychology, 22(1), 6-7.

2. Balin, S., Case, R., Coombs, J., \& Daniels, L. (1999). Conceptualizing critical thinking. Journal of Curriculum Studies, 31(3), 285-302.

3. Barak, M. \& Shakhman, L. (2008). Fostering higher order thinking in science class: Teachers reflections. Teachers and Teaching: Theory and Practice, 14(3), 191-208.

4. Bradford, A. (1987). Critical thinking in the workplace. Retrieved from www.faculty.umb.edu//Bradford/.../Critical\%20Thinking\%20\%\%20the $\% 20$ Workplace.doc

5. Browne, M. \& Freeman, K. (2000). Distinguishing features of critical thinking classrooms. Teaching in Higher Education, 5(3), 301-309.

6. Bughussian, P. (2006). Socratic pedagogy, critical thinking, and innate education. The Journal of Correctional Education, 57(1), 42-63.

7. Costa, A. (2001). Developing minds: A resource book for teaching thinking. $3^{\text {rd }}$ ed. ASCD:Alexandria, Va.

8. Elder, L. (2010). Reason to live. Times Higher Education. Retrieved from http://www.timeshighereducation.co.uk

9. $\quad$ Elder, L. (2011). Achieving critical mass. The Times Higher Education. Retrieved from http://www.timeshighereducation.co.uk/story.asp?sectioncode $=26 \&$ storycode $=414351 \& \mathrm{c}=1$ 
10. Ennis, R. (1989). Critical thinking and subject specificity: Clarification and needed research. Educational Researcher, 18 (April), 4-10.

11. Fasko, D. (2003). Critical thinking: Origins, historical development, future directions. In D. Fasko (Ed.), Critical thinking and reasoning: Current research, theory, and practice (pp. 3-18). Cresskill, NJ: Hampton Press.

12. Fung, I. Y. (2005). Collaborative reasoning: Critical thinking based learning and instruction. Unpublished doctoral dissertation, University of Auckland, New Zealand.

13. Gmelin, R. (2010). Another view: Education's about critical thinking, not technology. The Sacramento

Bee. Retrieved from www.criticalthinking.org/resources/news/index.cfm

14. Gross, K. (2009). What was I thinking? Inside Higher Ed. Retrieved from http://www.insidehighered.com/views/2009/03/16/gross

15. Hale, E. (2008). Project demonstrating excellence: A critical analysis of Richard Paul's substantive transdisciplinary conception of critical thinking (Doctoral dissertation). Retrieved from http://www.criticalthinking.org/files/Hale_PDE_Final.pdf

16. Halpern, D. (1998). Teaching critical thinking for transfer across domains. American Psychologist, 53(4), 449-455.

17. Halx, M. \& Reybould, L. (2005). A pedagogy of force: Faculty perceptions of critical thinking capacity in undergraduate students. The Journal of General Education, 54(4), 293-315.

18. Jackson, D. (2009). Obama urges education reform. USA Today. Retrieved from www.usatoday.com/news/washington/2009-03-10-obamaeducatin Nahtm

19. Johanson, J. (2010). Cultivating critical thinking: An interview with Stephen Brookfield. Journal of Developmental Education, 33(3), 26-30

20. Lehman, D. \& Nisbett, R. (1990). A longitudinal study of the aspects of undergraduate training on reasoning. Developmental Psychology, 26, 952-960.

21. Lester, G. (2000). Why bad beliefs don't die. Skeptical Inquirer, 24(6). Retrieved from http://www.csicop.org/si/archive/category/volume_

22. Lipman, M. (1995). Thinking in education. Cambridge University Press: Cambridge.

23. Mason, M. (2007). Critical thinking and learning. Educational Philosophy and Theory, 39(4), 339-349.

24. Mejia, A. \& Malinn, A. (2007). Are we promoting critical autonomous thinking? A discussion on controversial Genres and whether they can help us answer this question. Cambridge Journal of Education, 37(3), 409-426.

25. Moseley, D., Baumfield, V., Elliott, J., Gregson, M., Higgins, S., Miller, J. et al. (2005). Frameworks for thinking: A handbook for teaching and learning. Cambridge, MA: Cambridge University Press.

26. Nosich, G. (2009). Learning to think things through: A guide to critical thinking across the Curriculum (third edition). In S. Johnson \& L. Cramer (Eds.).

27. Pascarella, E. \& Terenzini, P. (2005). How college affects students. San Francisco: Jossey-Bass.

28. Paul, R. (1995). Critical thinking: How to prepare students for a rapidly changing world. In J. Willsen \& A. Binker (Eds.). Santa Rosa: Foundation for Critical Thinking.

29. Paul, R. \& Elder, L. (2006). Critical thinking: Tools for taking charge of your learning and your life ( $2^{\text {nd }}$ ed.). Upper Saddle River: Pearson/Prentice Hall.

30. Paul, R. \& Elder, L. (2010). The thinker's guide to analytic thinking. Dillon Beach, CA: Foundation for Critical Thinking Press.

31. Paul, R. Elder, L., \& Bartell, T. (1997). Study of 38 public universities and 28 private universities to determine faculty emphasis on critical thinking in instruction. Retrieved from http://www.criticalthinking.org/research/Abstract-RPAUL-38public.cfm

32. Plath, D., English, B., Connors, L., \& Beveridge, A. (1999). Evaluating the outcomes of intensive critical thinking instruction for social work students. Social Work Education, 18(2), 207-217.

33. Robinson, J. (2000). What are exploratory skills? The Workplace: Alabama Cooperative Extension System, 1(3), 1-3.

34. The Foundation for Critical Thinking. (1995). The critical thinking community: Our concept of critical thinking. Retrieved from http://www.criticalthinking.org/aboutCT/ourConceptCT.cfm

35. Tishman, S., Perkins, D., \& Jay, E. (1995). The thinking classroom: Learning and teaching in a culture of thinking. Boston: Allyn and Bacon. 
36. Tsui, L. (2008). Cultivating critical thinking: Insights from an elite liberal arts college. The Journal of General Education, (56), 200-227.

37. Van Gelder, T. (2005). Teaching critical thinking: Some lessons from cognitive science. College Teaching, 53(1), 41-46.

38. Walters, K. S. (1994b). Introduction: Beyond logicism in critical thinking. In K. S. Walters (Ed.), Rethinking reason: New perspectives in critical thinking (pp. 1-22).

39. Albany: State University of New York Press.Wright, I. (2002). Challenging students with the tools of critical thinking. The Social Studies, 93(6), 257-261. 


\section{APPENDIX A}

Crifieal Thinding: Barie Theory \& Instructiowal Stuctures

\section{Universal Structures of Thought}

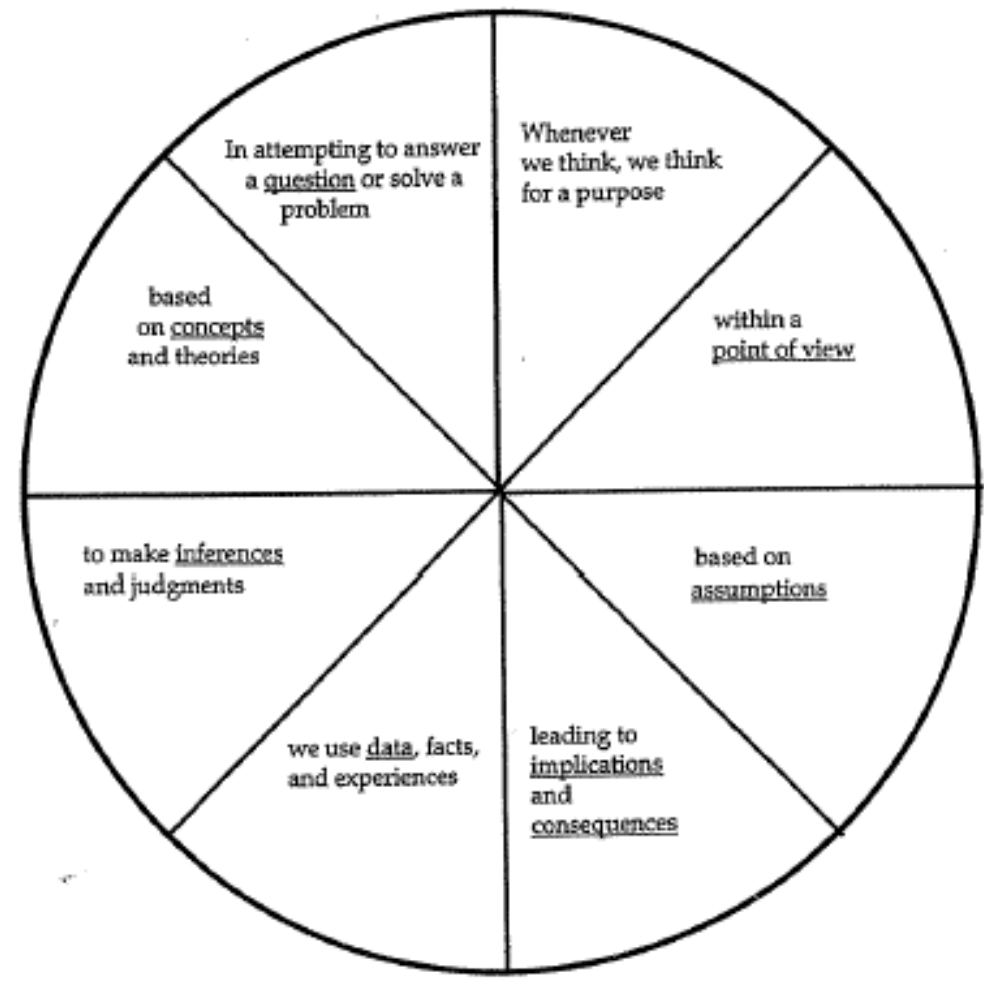

3-12

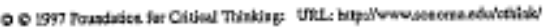

The Universal Structures Of Thought

From "Critical Thinking: Basic Theory \& Instructional Structures," by The Foundation for Critical Thinking (www.criticalthinking.org), p. 3-12. Copyright 1999 by The Foundation for Critical Thinking. Reprinted with permission. 


\section{APPENDIX B}

Critical Thinling; Basis Theary \& Hestructional Shachures
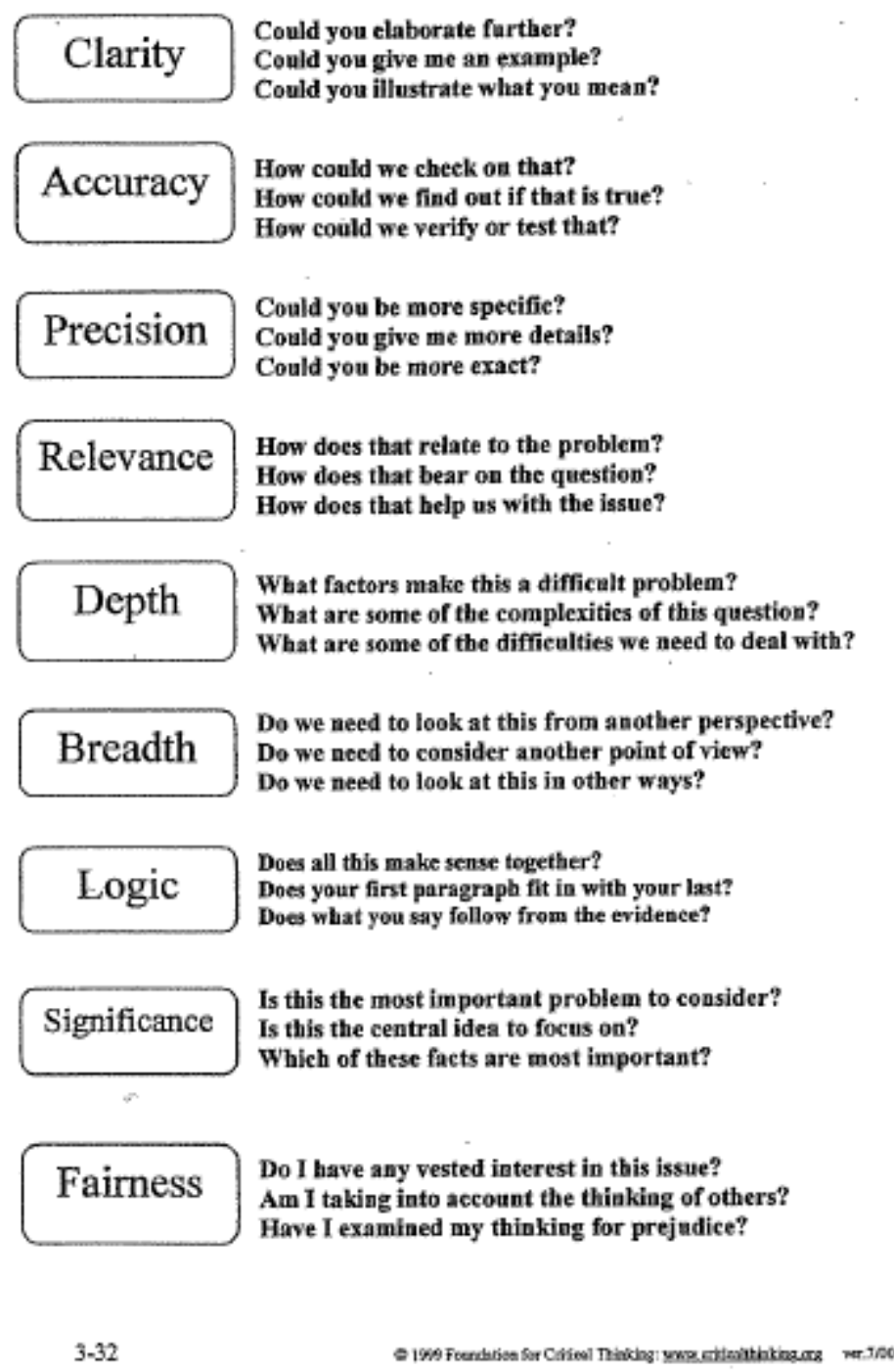

The Universal Intellectual Standards

From "Critical Thinking: Basic Theory \& Instructional Structures," by The Foundation for Critical Thinking (www.criticalthinking.org), p. 3-32. Copyright 1999 by The Foundation for Critical Thinking. Reprinted with permission. 


\section{APPENDIX C}

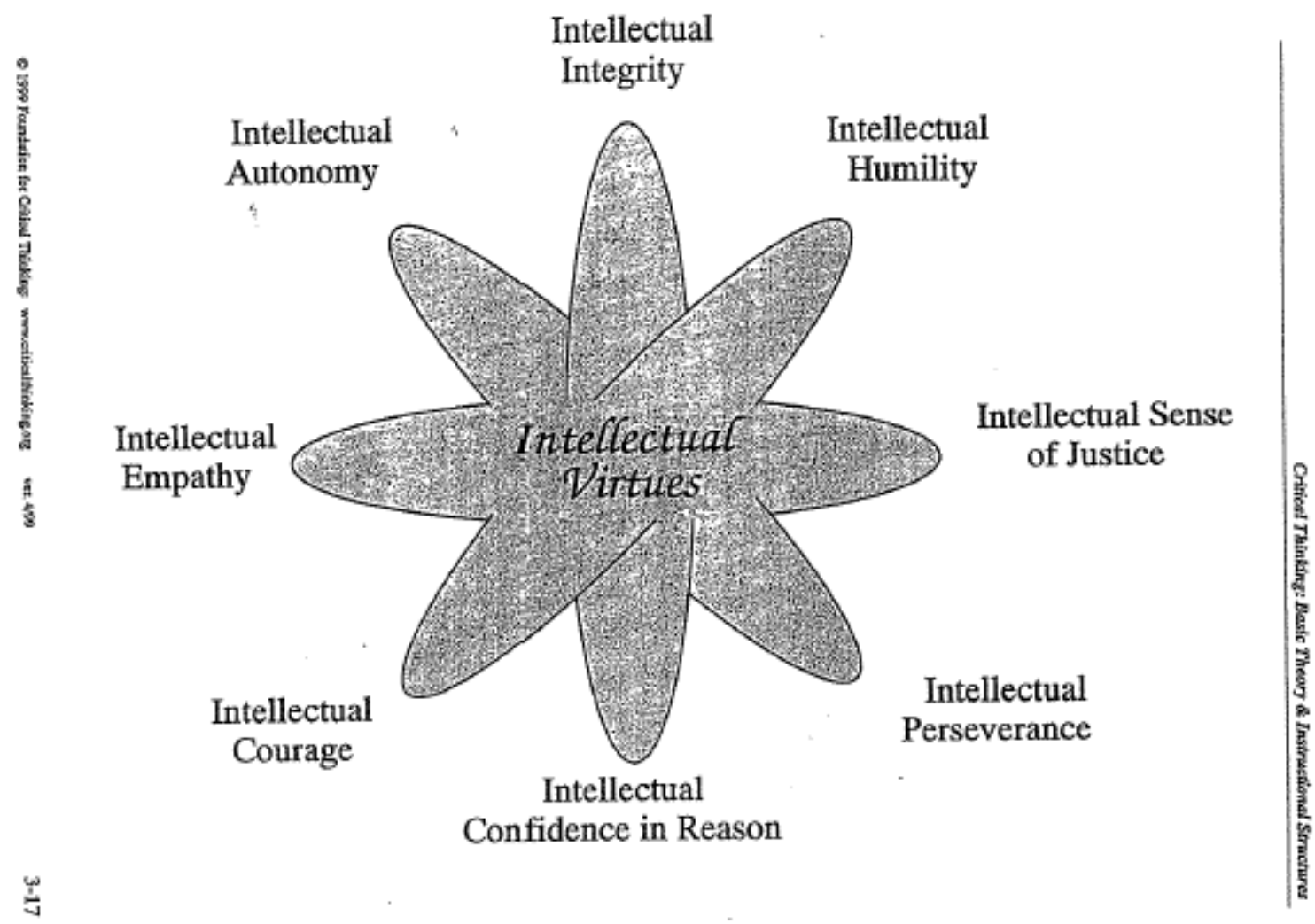

The Intellectual Traits Of Mind

From "Critical Thinking: Basic Theory \& Instructional Structures," by The Foundation for Critical Thinking (www.criticalthinking.org), pp. 3-17. Copyright 1999 by The Foundation for Critical Thinking. Reprinted with permission. 